\title{
The treatment of hypertension in the elderly
}

\author{
Miriam Chellingsworth ${ }^{1}$ and D.G. Beevers ${ }^{2}$ \\ ${ }^{1}$ Department of Clinical Pharmacology and Therapeutics, Queen Elizabeth Hospital, Birmingham, and \\ ${ }^{2}$ Department of Medicine, Dudley Road Hospital, Birmingham, UK.
}

Many important issues relating to the treatment of mild and modern hypertension in the elderly remain to be resolved. However, the results of the European Working Party on Hypertension in the Elderly trial have answered some questions, and will probably change the views of many on the treatment of hypertension in the elderly patients (Amery et al., 1985).

\section{The size of the problem}

This is difficult to measure until a working definition of high blood pressure for the elderly is defined. Crosssectional studies have shown blood pressure to rise with age at least until the age of 70 . The average diastolic blood pressure then falls (Anderson \& Cowan, 1959; Master et al., 1958), but systolic pressure continues to rise. Some longitudinal studies have shown a less marked effect of age (Kannel et al., 1981) and, in some primitive populations, blood pressure does not rise with age at all. The World Health Organization has defined hypertension as a blood pressure greater than $160 / 95 \mathrm{mmHg}$ (World Health Organisation, 1978); the Framingham study also used this definition. If a single, casual blood pressure reading of $160 / 95 \mathrm{mmHg}$ is taken, then the prevalence of hypertension approaches $50 \%$ in some elderly populations, with a further $13 \%$ having isolated systolic hypertension (Cholandrea et al., 1970). However, if a series of measurements is taken these figures fall dramatically (Wing et al., 1982). The value of treating a person with hypotensive drugs after only one raised blood pressure reading is not known, yet most epidemiological studies relating prognosis to blood pressure are based on single casual readings.

Correspondence: M. Chellingsworth, B.M., M.R.C.P., Accepted: 10 September 1985

\section{Systolic hypertension}

Isolated or disproportionate systolic hypertension is commoner in the elderly. Studies have shown it to be an important risk factor in the development of complications, particularly stroke (Kannel et al., 1981). The best treatment for systolic hypertension is not yet known, though the sub-group with low renin levels may respond well to thiazide diuretics (Niarchos \& Laragh, 1984). Studies of the orally active angiotensin converting enzyme inhibitor, enalapril, suggest that this class of drug is better at reducing systolic blood pressure than beta-blockers or thiazides (Enalapril in Hypertension Study Group, 1984). The pathogenesis of isolated systolic hypertension is thought to be the increasing arterial rigidity and decreasing arterial compliance in old age (Simon et al., 1979), though this is by no means certain. There is as yet no published trial of the treatment of isolated systolic hypertension although one group has shown that control of systolic blood pressure in the elderly with systolic/diastolic hypertension reduced the incidence of adverse effects (Applegate et al., 1982). A randomized controlled trial of the treatment of isolated systolic hypertension is currently under way in the USA but results are not expected for at least 5 years.

\section{Effect of blood pressure on morbidity and mortality in} the elderly

Some British studies have failed to show any relationship between hypertension and excess morbidity and mortality in the elderly (Hodkinson \& Exton-Smith, 1976; Evans, 1983; Droller et al., 1952; Anderson \& Cowan, 1976), particularly in those over 80 years. Some have even suggested a protective effect of hypertension in the elderly (Rajala et al., 1983). These findings seem odd in the face of the fact that hypertension is known to have adverse effects in younger

(C) The Fellowship of Postgraduate Medicine, 1986 
patients (Hypertension Detection and Follow-up Cooperative Group, 1982). There may be a tendency for those individuals at risk of dying from their hypertension to do so before reaching old age. However, this cannot be the whole explanation, as large trials are now beginning to show a reduction in morbidity and mortality in those elderly people whose hypertension is treated.

\section{Summary of the early trials involving elderly patients}

In 1968, Priddle and co-workers (1968) in a study of elderly hypertensives in Toronto, showed a reduced mortality rate in the treated patients. However, the study was small, and not randomized or double-blind.

The Veterans Administration Cooperative Study on Antihypertensive Agents (1972) showed that, in patients over 50 years of age with cardiovascular or renal abnormalities who had a diastolic blood pressure of $90-104 \mathrm{mmHg}$ the treatment of hypertension significantly reduced cardiovascular complications. However, it is always unsafe to look only at small subgroups in a trial that was not designed specifically for the elderly, so the results are not conclusive.

The National Heart Foundation of Australia study (1981) of mild hypertension included 582 subjects aged 60 to 69 years at entry. Their diastolic blood pressures were between 95 and $109 \mathrm{mmHg}$. Half were randomized to receive active treatment, and, in this group there was a $39 \%(P<0.025)$ reduction in death and cardiovascular events. The trial did not contain enough patients to be certain of the benefits of treatment in the elderly, which was also a sub-group of a larger study of mild hypertension.

In the highly controversial Hypertension Detection and Follow-Up Program (Hypertension Detection and Follow-up Cooperative Group, 1982) there was also a significant reduction in mortality in the subgroup aged 60 to 69 who were randomized to 'stepped care' of their hypertension rather than those referred to the care of their family practitioners.

The first results of the MRC trial of treatment of mild hypertension have recently been published (MRC Working Party, 1985). However, no patient older than 64 years was entered into the study, and, as yet, the mortality and morbidity in different age groups has not been revealed.

\section{The European Working Party on Hypertension in the Elderly}

The EWPHE study is a large, multicentre, doubleblind, randomized trial, specifically designed to show the effects of treatment of mild hypertension in patients of 60 to 100 years of age (mean age 72 years). Because it was started in the early 1970s the treatment regimen chosen (hydrochlorothiazide an triameterene, with methyldopa added if necessary) $\overrightarrow{\phi s}$ now rather outdated. The trial has now been terminated because of a significant (36\%) reduction in cardiovascular events in the treatment group. $\mathrm{Ca} \mathrm{f}_{-}$ diovascular mortality was also reduced, as wege cerebrovascular 'events' but not cerebrovascular mo tality (Amery et al., 1985). There was no significa difference in overall mortality in treated or contri patients. This is not unexpected because as soon aspa reduction in cardiovascular mortality was shown, the trial was terminated. There was a $26 \%$ reduction total mortality in the treated group, and, if the triat had been continued for longer, this difference migh have become significant.

The reduction of cerebrovascular events is important as in elderly people stroke-free survival may more important than just prolongation of life. The reduction in cardiovascular mortality is significant: this has not been shown in other trials of treatment of mild hypertension. It is surprising then, that it shoufd be found in the elderly - a group who would already be expected to have developed atherosclerosis. The mechanism of this 'cardioprotection' by antihypertensive drugs is, therefore, open to question.

Although minor changes in biochemistry (mite hypokalaemia and slight increases in blood glugose and serum uric acid) were seen, no significant inctease in adverse effects was noted in the active treatinest group, and the drugs used appeared to be $\vec{w}$ ell tolerated (European Working Party on Hypertension in the Elderly, 1983). The initial report of EWPH does not provide any information on the benefits of treating hypertension in the various age groups ov the age of 60 years but when the sub-group analyses $\$$ become available, great care must be exercised in then interpretation. However, we do need to know whether the benefits of antihypertensive treatment are the same in patients of 60 to 70 years as in those of 70 to 80 years or even those of 80 to 90 years. Most EWPHE patien were hospital attenders and they are not, therefore; typical of fit, ambulant, hypertensive patients who age not hospital attenders. The British General Practize trial of treatment of hypertension in the elderly to Be published later this year (Coope, 1982), should give the results of treating a more typical group of elderiy hypertensives. Any group of elderly hypertensives widi be very heterogeneous - some will be fit, some not, some frail, some strong. The EWPHE trial cannot extrapolated to all patients of 60 years of age or mores

In summary, the EWPHE trial has shown a sisnificant reduction in adverse cardiovascular events $\dot{\varphi}$ the treated group. This, and several other studies have therefore shown that treatment of hypertension in the elderly is safe and worthwhile. The actively treatel groups do not contain an excess number of 'drop-ou华" 
due to treatment side effects (European Working Party on Hypertension in the Elderly, 1983).

\section{Choice of drug for the elderly hypertensives}

There is relatively little information specifically on treatment of the elderly with hypotensive drugs. However, this should soon change following recent recommendations of the Committee on Safety of Medicines (Committee on Safety of Medicines Update, 1985), that new drugs should be tested in the elderly before being licensed.

\section{Diuretics}

The EWHPE and several other trials have confirmed the safety and efficacy of thiazide diuretics in elderly hypertensives. However, they are not without their problems; serum potassium levels should be checked, and especially in those who are also receiving digoxin, potassium supplements or potassium sparing agents are needed. Diabetes mellitus, hyperlipidaemia, gout, urinary incontinence and prostatism, all of which are commoner in the elderly, are relative contraindications.

\section{$\beta$-adrenergic blockers}

Blockers are widely used and well tolerated in most elderly patients (Hamdy et al., 1982; Hosie et al., 1983). There is, however, some evidence that these drugs are less effective in older patients (Schocken \& Roth, 1977) although this has not been formally investigated. The pharmacokinetics of propranolol and metoprolol (Schneider et al., 1980; Schneck et al., 1980; Quarterman et al., 1981) are probably little altered in fit elderly people, but this does not apply to hospitalized patients (Castleden \& George, 1979). Water soluble drugs such as atenolol which are mainly excreted by the kidney may reach much higher blood levels in the elderly, and should, in theory, be given in reduced dosage (Kurch \& Gorg, 1982) although, in practice, higher doses are tolerated (O'Callaghan et al., 1983). Beta-blockers have been found to protect against the hypokalaemic effect of thiazides (Coope, 1982). Labetalol, a combined alpha- and beta- blocker is well tolerated and effective in the elderly in small doses (Eisalo \& Virta, 1982). Of course, contraindications which apply in young patients also apply in the elderly, and a large number of elderly patients are excluded from treatment because of the high incidence of chest and peripheral vascular disease in this age group.

\section{Centrally acting drugs}

Methyldopa has been proved to be effective in the EWPHE trial. However, it is no longer the drug of first choice in young patients because of its central side effects (sedation and depression) and the occasional occurrence of haemolytic anaemia.

Clonidine is also effective in the elderly and in systolic hypertension (Weber et al., 1983), but is no longer widely used because of the rebound hypertensive effect on missing a dose. This may be very important in the forgetful elderly patient.

\section{Reserpine}

Reserpine, an adrenergic blocking drug has been advocated for treatment of the elderly hypertensive (Luxenberg \& Feigenbaum, 1983). However, it is not widely used in the UK, because of a high incidence of depression and even suicide. It is, however, widely used in the USA and when given in low doses and at night may be well tolerated.

\section{Vasodilators}

Theoretically these are the drugs of choice in the elderly with predominant systolic hypertension, but there have been no large trials to prove this point. Prazosin has been used with good effect in the elderly but requires careful clinical supervision because of occasional severe postural hypotension after the first dose. The initial dose should be small, but can be increased quite rapidly.

Hydralazine is well tolerated in the elderly. Its metabolism by acetylation (Farah et al., 1977) in the liver is little affected by age. As in younger patients, it may cause a syndrome resembling systemic lupus erythematosus. One small short-term trial has shown that nifedipine is effective and generally well tolerated in the treatment of hypertension in the elderly, including those with isolated systolic hypertension (Stessmann et al., 1985), and it has been claimed that it is more effective in older patients (Buhler, 1983).

The angiotensin converting enzyme (ACE) inhibitors have not been assessed in the elderly, but possible beneficial effects, particularly on systolic pressures, makes this group theoretically attractive. However, in patients already receiving diuretic therapy, who may be volume depleted, great caution should be exercised, as ACE inhibitors may cause a precipitate drop in blood pressure. As plasma renin levels are lower in older patients (Niarchos \& Laragh, 1984), in theory the ACE inhibitors might be less effective, but there is little information on this point.

In summary, the EWPHE trial has shown a significant reduction in cardiovascular events and mortality, a significant reduction in cerebrovascular 
events, and a non-significant reduction in cerebrovascular mortality in patients over 60 with mild to moderate hypertension. Perhaps because the trial was terminated early, only a non-significant reduction in total mortality occurred in the treated group. For the first time, a small but significant benefit from treating hypertensives over age 60 has been shown: the large size of the problem makes the financial consequences

\section{References}

AMERY, A., BIRKENHAGER, W., BRIXKO, P. and members of the Working Party.(1985). Mortality and morbidity results from the European Working Party on high blood pressure in the elderly trial. Lancet, i, 1349.

ANDERSON, W.F. \& COWAN, N.R. (1959). Arterial pressure in healthy older people. Clinical Science, 18, 103.

ANDERSON, F. \& COWAN, N.R. (1976). Survival of healthy older people. British Journal of Preventative and Social Medicine, 30, 231.

APPLEGATE, W.B., VAN DER ZWAAG, R., DISMUKE, S.E. \& RUNYAN, J.W.(1982). Control of systolic blood pressure in elderly black patients. Journal of the American Geriatric Society, 30, 391

BUHLER, F. (1983). Age and cardiovascular response adaptation. Determinants of an antihypertensive treatment concept primarily based on beta blockers and calcium entry blockers. Hypertension, Suppl. III, 94.

CASTLEDEN, C.M. \& GEORGE, C.F. (1979). The effect of ageing on the hepatic clearance of propranolol. British Journal of Clinical Pharmacology, 7, 49.

CHOLANDREA, M., FRIEDMAN, G.D., NICHMAN, M.Z. \& LYND, C.N. (1970). Systolic hypertension in the elderly An epidemiologic assessment. Circulation, 41, 239.

COMMITTEE ON SAFETY OF MEDICINES UPDATE. (1985). Drugs and the elderly. British Medical Journal, 291, 1345.

COOPE, J. (1982). A trial of treatment of hypertension in the elderly in General Practice. Acta Medica Scandinavica, 676 (Suppl.), 141.

DROLLER, H., PEMBERTON, J., ROSEMAN, C. \& GROUT, J.L.A. (1952). High blood pressure in the elderly. British Medical Journal, 2, 968.

EISALO, A. \& VIRTA, P. (1982). Treatment of hypertension in the elderly with labetalol. Acta Medica Scandinavica, 665 (Suppl.), 129.

ENALAPRIL IN HYPERTENSION STUDY GROUP (UK). (1984). Enalapril in essential hypertension: a comparative study with propranolol. British Journal of Clinical Pharmacology, 18, 51.

EUROPEAN WORKING PARTY ON HYPERTENSION IN THE ELDERLY. (1983). The progress of patients in the EWPHE trial. Acta Medica Scandinavica, 676 (Suppl.), 119.

EVANS, J.G. (1983). Hypertension and stroke in an elderly population. Acta Medica Scandinavica, 676 (suppl.), 22.

FARAH, F., TAYLOR, W., RAWLINS, M. \& JAMES, O. (1977). Hepatic drug acetylation and oxidation - effects of ageing in man. British Medical Journal, 2, 155.

HAMDY, C., TOVEY, D., BABER, N.S. \& MCAINSH, J. (1982). Use of long-acting propranolol (Inderal LA) in the management of elderly hypertensive patients. European Journal of Clinical Pharmacology, 22, 379. of this enormous. Present evidence does, howevero suggest that the elderly with repeated high bloo\& pressure readings should be treated, and that they cax be treated safely. Ideally, the EWPHE trial would be repeated using more up-to-date therapeutic agents but: clearly the results of such a study would not $b \overline{\bar{E}}$ available for many years.

HODKINSON, H.M. \& EXTON-SMITH, A.N. (1976). Factors predicting mortality in the elderly in the community. Age and Ageing, 5, 110.

HOSIE, J., VALLEE-JONES, J. \& CLIFFORD, P.D. (1983). Long term use of Prestim (Timolol/Bendrofluazide) in the management of mild to moderate hypertension in Generä. Practice. British Journal of Clinical Practice, 11/12, 393 HYPERTENSION DETECTION AND FOLLOW-UR COOPERATIVE GROUP. (1982). Five year findings QS $^{\circ}$ H.D.F.P. III. Reduction in stroke incidence among petsons with raised blood pressure. Journal of the America@ Medical Association, 247, 633.

KANNEL, W.B., WOLF, P.A., MCGEE, P.L., DAWBER, T.R $\vec{\varepsilon}$ MCNAMARA, P. \& CASTELLI, W.P. (1981). Systolic bloog pressure, arterial rigidity and risk of stroke: The Framin gham Study. Journal of the American Medical Association 245, 1225.

KURCH, W. \& GORG, K.G. (1982). Clinical pharmacokine⿻日乚 $\vec{c}$ of atenolol - A review. European Journal of Drug Metaso? ism and Pharmacokinetics, 7, 81-91.

LUXENBERG, J. \& FEIGENBAUM. (1983). The use reserpine for elderly hypertensive patients. Journal of the American Geriatric Society, 31 (9), 556.

MASTER, A.M., LASSER, R.P. \& JAFFE, H.L. (1958). Bloo㫣 pressure in white people over 65 years of age. Annals of Internal Medicine, 48, 284.

MEDICAL RESEARCH COUNCIL WORKING PARTY (1985) MRC trial of treatment of mild hypertension: principat results. British Medical Journal, 291, 97.

NATIONAL HEART FOUNDATION OF AUSTRALIA. (1981) Treatment of mild hypertension in the elderly. Medica Journal of Australia, 68, 398.

NIARCHOS, A.P. \& LARAGH, J.H. (1984). Effect of diuretie therapy in low, normal and high renin isolated systolig hypertension. Americal Journal of Cardiology, 53, 797.

O'CALLAGHAN, W.G., LAHER, M.S., MCGARRY, K., O'BRIEN, E. \& O'MALLEY, E. (1983). Antihypertensive an $\$$ renal haemodynamic effects of atenolol and nadolol in elderly hypertensive patients. British Journal of Clinic Pharmacology, 16, 417.

PRIDDLE, W.W., LIU, S.F., BREITHAUPT, D.J. \& GRANT, P. T़ (1968). Amelioration of high blood pressure on the elderlyn. Journal of the American Geriatric Society, 16, 887.

QUARTERMAN, C.P., KENDALL, M.J. \& JACK, D.B. (1981) The effect of age on the pharmacokinetics of metoprolo and its metabolites. British Journal of Clinical Pharo macology, 11, 287.

RAJALA, S., HAAVISTO, M., HEIKINHEIMO, R. \& MATTILA K. (1983). Raised blood pressure and mortality in the veryo old. Lancet, ii, 520 . 
SCHNECK, D.W., LUDERER, J.R., PRITCHARD, J.E., VARY, J.E., DEWITT, F.O., BEWQ, J.C. \& HAYES, A.H. (1980). A comparison of the intrinsic clearance of propranolol in young and elderly subjects. Journal of Clinical Pharmacology and Therapeutics, 27, 284.

SCHNEIDER, R.E., BISHOP, H., YATES, R.A., QUARTERMAN, C.P. \& KENDALL, M.J. (1980). Effect of age on plasma propranolol levels. British Journal of Clinical Pharmacology, 10, 169.

SCHOCKEN, D. \& ROTH, G. (1977). Reduced beta adrenergic receptor concentrations in ageing man. Nature, 267, 856.

SIMON, A.C., SAFAR, M.A., LEVENSON, J.P., KHEDER, A.M. \& LEVY, B.I. (1979). Systolic hypertension: haemodynamic mechanisms and choice of antihypertensive treatment. American Journal of Cardiology, 44, 505.

STESSMANN, J., LIEBEL, B., YOGIL, Y., ELICKIM, R. \& BENISHAY, D. (1985). Nifedipine in the treatment of hyperten- sion in the elderly. Journal of Clinical Pharmacology, 25, 193.

VETERANS ADMINISTRATION COOPERATAIVE STUDY GROUP ON ANTIHYPERTENSIVE AGENTS. (1972). Effects of treatment on morbidity in hypertension. III Influence of age, diastolic pressure and prior cardiovascular disease. Circulation, 45, 991.

WEBER, M.A., DRAYER, J.I.M. \& GRAY, D.R. (1983). Combined diuretic and sympatholytic therapy in elderly patients with predominant systolic hypertension. Chest, 83, 416 .

WING, S., AUBERT, R., HANSEN, J.P., HARNES, C.G., SLOME, C. \& TYROLER, H.A. (1982). Isolated systolic hypertension in Evans County. 1. Prevalence and screening considerations. Journal of Chronic Diseases, 35, 735.

WORLD HEALTH ORGANISATION. (1978). Arterial hypertension. WHO Technical Report Series No. 628. 